\title{
A Co-Polarization Broadband Radar Absorber for RCS Reduction
}

\author{
Thtreswar Beeharry ${ }^{1,2, *}$, Riad Yahiaoui ${ }^{1}$, Kamardine Selemani ${ }^{2}$ \\ and Habiba Hafdallah Ouslimani ${ }^{1}$ \\ 1 Laboratoire Energétique Mécanique Electromagnétisme, Université Paris Nanterre, 92410 Ville d'Avray, \\ France; ryahiaoui@u-paris10.fr (R.Y.); habiba.ouslimani@parisnanterre.fr (H.H.O.) \\ 2 Constructions Mécanique de Normandie, Systems department, 50105 Cherbourg, France; \\ kselemani@cmn-cherbourg.com \\ * Correspondence: tbeeharry@cmn-cherbourg.com
}

Received: 23 August 2018 ; Accepted: 7 September 2018; Published: 9 September 2018

\begin{abstract}
In this article, a single layer co-polarization broadband radar absorber is presented. Under normal incidence, it achieves at least $90 \%$ of absorption from $5.6 \mathrm{GHz}$ to $9.1 \mathrm{GHz}$ for both Transverse Electric (TE) and Transverse Magnetic (TM) polarizations. Our contribution and the challenge of this work is to achieve broadband absorption using a very thin single layer dielectric and it is achieved by rotating the resonating element by $45^{\circ}$. An original optimized Underlined $U$ shape has been developed for the resonating element which provides a broadband co-polarization absorption. The structure is 12.7 times thinner than the wavelength at the center frequency. To understand the absorption mechanism, the transmission line model of an absorber and the three near unity absorption peaks at $5.87 \mathrm{GHz}, 7.16 \mathrm{GHz}$ and $8.82 \mathrm{GHz}$ have been used to study the electric and magnetic fields. The physical insight of how the three near unity absorption peaks are achieved has also been discussed. After fabricating the structure, the measurements were found to be in good agreement with the simulation results. Furthermore, with the proposed original UUSR resonating element, the operational bandwidth to thickness ratio of 6.43 is obtained making the proposed UUSR very competitive.
\end{abstract}

Keywords: absorber; broadband; single layer; rcs reduction

\section{Introduction}

Since the first successful experimental work on Metamaterials (MMs) reported by Smith et al. [1], various metamaterial-based applications have been developed covering low to optical frequencies [2-8]. MMs are no longer only a research field; they have now in fact proven to be successful in industrial solutions. MMs have been deployed for several applications such as compact antennas [9], invisible cloaking [10], super lenses [11] and sensing [12] to name but a few. MMs are also useful candidates for electromagnetic wave absorbers [13-15]. Nowadays, absorbers are required for Electro-Magnetic Compability (EMC) and stealth (radar cross section) applications. Broadband capability in defense and EMC applications of MMs is limited by their resonant structures providing narrow bandwidth. Extensive research on narrow band [16,17], multiband [18,19] and large band [20-22] Metamaterial Absorbers (MAs) have been published. To enlarge the bandwidth, two of the most used techniques consist of incorporating resonating elements working at nearby frequencies arranged on the same plane [23] or stacked on several layers [24]. Both techniques lead to a drop in the absorption (sometimes the reflection coefficient $\mathrm{S} 11>-10 \mathrm{~dB}$ ) at certain frequencies in the bandwidth. Using several elements on the same plane is very difficult to implement due to lack of space in a small unit cell. On the other hand, multiple layers can considerably increase the total height of the structure which is not 
desired for many applications. Using well customized magnetic materials can decrease the height [25] but they can be very expensive. Using active components [26,27] such as diodes can improve bandwidth and absorption but some defense applications require the least possible external electronic sources. Some recent works $[28,29]$ have shown that broadband absorption using simple shapes of resonating elements can be achieved but the use of materials such as Titanium, Tin Oxide or complicated fabrication processes makes the absorbers more costly. Replacing the metallic resonating elements by well designed resistive sheets [30] can provide broadband absorption but depending on the values $(\Omega /$ Square) it is sometimes very difficult to manufacture them due to limited technology. For these reasons, thin broadband MAs designed with easily available dielectrics especially for low frequencies and the gigahertz regime are very complicated to design and are a challenging topic. In this paper, we present a thin broadband MA of $3.5 \mathrm{GHz}$ of bandwidth operating in the band of 5.6 GHz to $9.1 \mathrm{GHz}$ achieving more than $90 \%$ of co-polarization absorption in the whole band at normal incidence. The co-polarization absorption rate remains more than $50 \%$ until $40^{\circ}$ of oblique incidence for both Transverse Electric (TE) and Transverse Magnetic (TM) polarizations. As it will be seen in the Design section, the resonator (only the metallic Underlined U shape) is rotated by $45^{\circ}$ and due this rotation the cross-polar absorption is not significant. Depending on applications, not achieving cross-polar absorption is more or less critical. Inside radomes of military vessels for example, cross-polar absorption is not often required for the reduction of electromagnetic interference.

\section{Results}

\subsection{Design of the Unit Cell}

The unit cell of the absorber is illustrated in Figure 1. It consists of a metallic Underlined U Shaped Resonator (UUSR) deposited on a metal backed FR4 dielectric. The UUSR is axially rotated by $45^{\circ}$. The FR4 dielectric is $3.2 \mathrm{~mm}$ thick and is backed with metal to prevent transmission. A $0.017 \mathrm{~mm}$ thin copper having electric conductivity of $5.8 \times 10^{7} \mathrm{~S} / \mathrm{m}$ was used for the UUSR and to back the FR4. The FR4 has a permittivity of 3.92 and loss tangent of 0.025 . The unit cells are arranged in periods of $\mathrm{P}=15 \mathrm{~mm}$. Numerical design and simulations were performed using the commercial software CST Design Studio Suite 2018. Periodic boundary conditions were applied in the numerical model in order to mimic a 2D infinite structure. The dimensions in milliliters $(\mathrm{mm})$ are as follows. $\mathrm{W} 1=2.5, \mathrm{~W} 2=7.85$, $\mathrm{W} 3=1.8, \mathrm{~W} 4=2.85, \mathrm{~W} 5=7.85, \mathrm{~W} 6=8, \mathrm{~W} 7=0.175, \mathrm{~L}=4.35, \mathrm{P}=15, \mathrm{~h}=3.2$. The USSR is centered at $(\mathrm{x}=-0.112611, \mathrm{y}=0.112611)$.

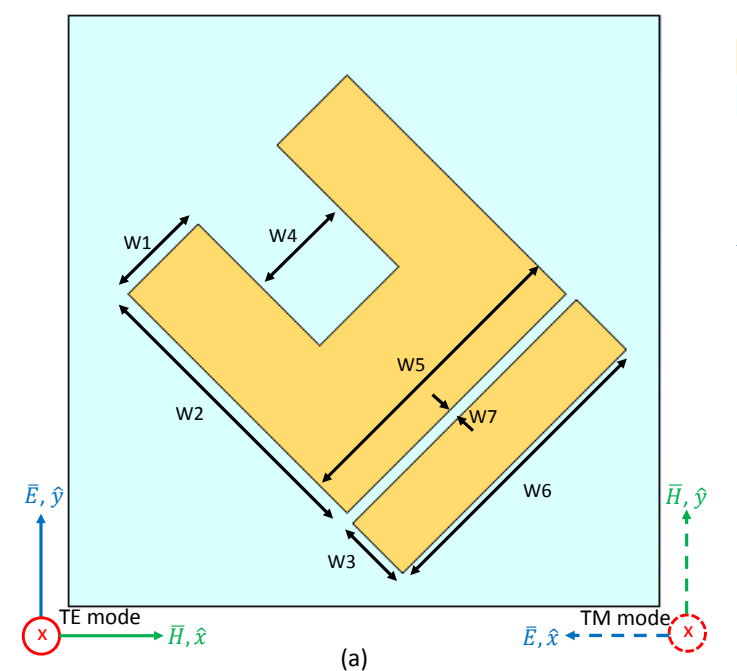

(a)

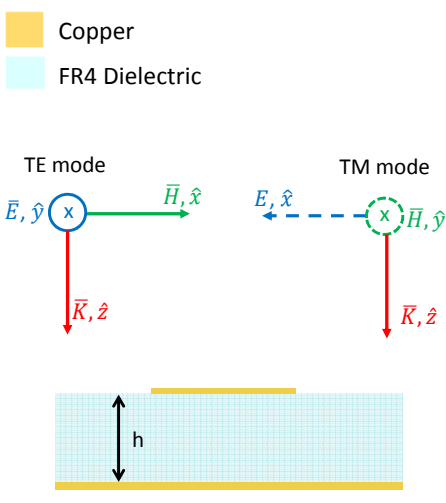

(b)

Figure 1. (a) Top view of the unit cell of the proposed absorber, (b) Cross sectional view of the uniet cell. 


\subsection{Simulation Results}

The co-polarization absorption rate for normal and oblique incidences of linearly polarized TE and TM waves of our structure is presented in Figure 2. The figure indicates that, for both TE and TM polarizations, for normal incidence and oblique incidences until $20^{\circ}$, the absorption rate is more than $90 \%$ in the whole range of $5.6-9.1 \mathrm{GHz}$ frequency band. The absorption rate is more than $85 \%$ and $77 \%$ for $30^{\circ}$ and $40^{\circ}$ respectively. Three near unity absorption peaks have been observed at $5.86 \mathrm{GHz}$, $7.16 \mathrm{GHz}$ and $8.82 \mathrm{GHz}$ and are be used to understand the absorption mechanism in the next chapter.

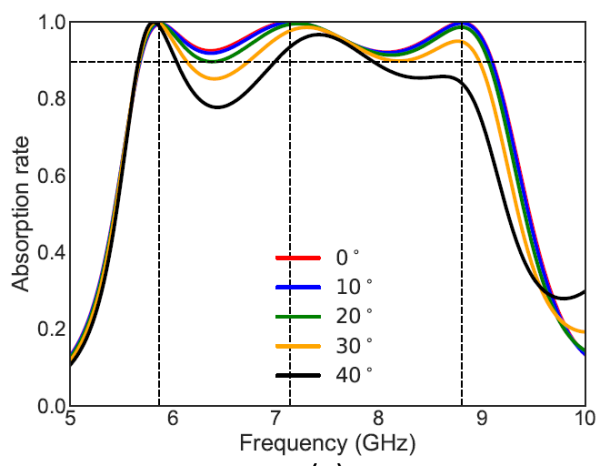

(a)

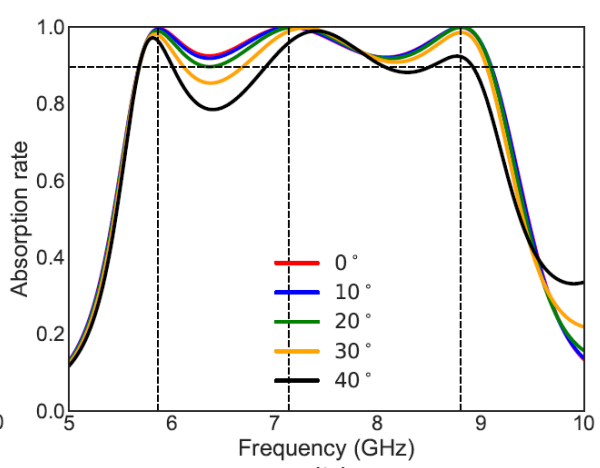

(b)

Figure 2. Absorption rate for normal and oblique incidences for (a) linearly polarized TE wave and (b) linearly polarized TM wave.

As described in the introduction, the broadband absorption is obtained by rotating the UUSR by $45^{\circ}$. This strategy has been adopted in some recent works such as [24]. To understand how broadband absorption is obtained, the absorption results for both TE and TM linearly polarized waves of the absorber is presented for two cases in Figure 3. The first case (Case 1) represents the unrotated UUSR and the second case (Case 2) represents the UUSR rotated by $45^{\circ}$. The UUSR has been inspired from $U$ shapes which exhibit capacitive response due to gap between the two arms. The whole shape was then optimized using CST Studio.

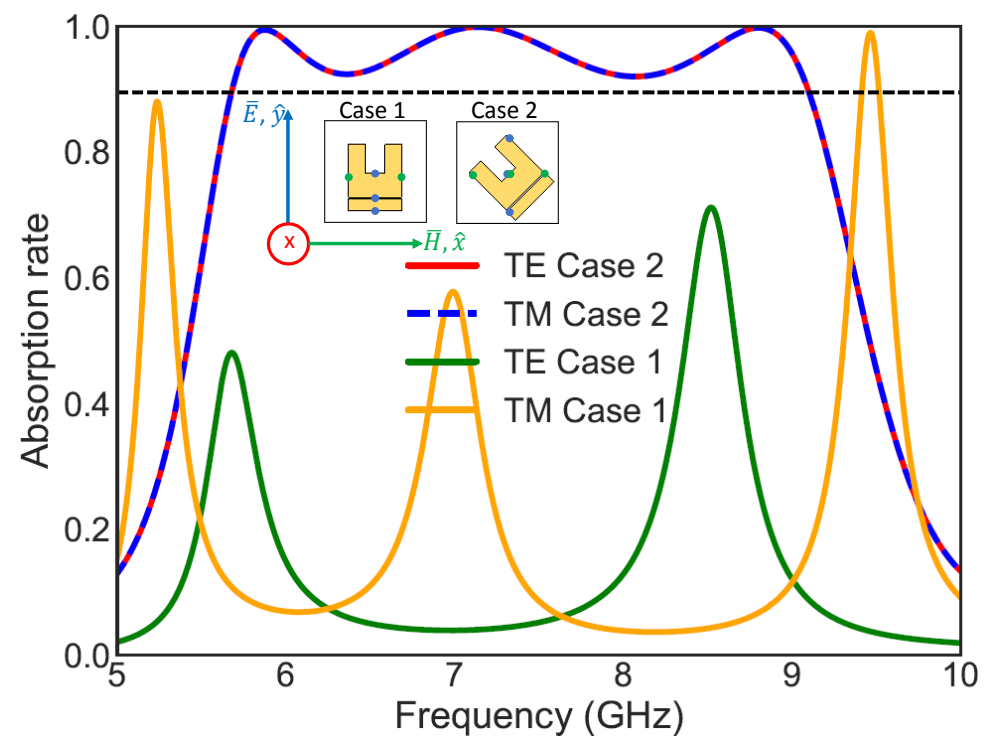

Figure 3. Absorption rates for linearly polarized TE and TM waves for Case 1 and Case 2. 
For the first case (Case 1), when the UUSR is not rotated the segments of the patch (UUSR) excited by the electric field (blue points on the patch) is not the same as the segments excited by the magnetic field (green points on the patch). Hence, the absorption rates for TE represented by the green curve and TM represented by orange curve are not the same. Moreover, broadband absorption is not achieved. Therefore, the patch oriented as in case 1 is not efficient. When the UUSR is rotated by $45^{\circ}$, as in Case 2 , the structure becomes more interesting as the electrical and magnetic field interact with exactly the same segments of the patch. TE and TM modes become equal as shown by red and blue curves. Furthermore, the absorption is considerably increased and broadened.

\subsection{Absorption Mechanism}

To understand the absorption mechanism the transmission line model of an absorber can be considered. One straight forward solution to design a radar absorber is to place a complex sheet (surface providing complex impedance) over a grounded dielectric as shown in Figure 4 . The complex sheet is designed in a way that the whole structure matches the impedance of the free space $\left(Z_{0}=377 \Omega\right)$. Three parameters are important for the design of the absorber: the thickness and permittivity of the dielectric substrate and the geometrical parameters of the complex sheet.

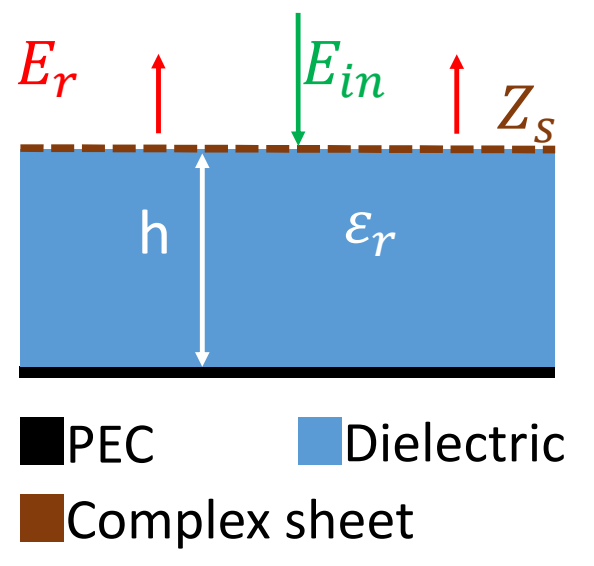

(a)

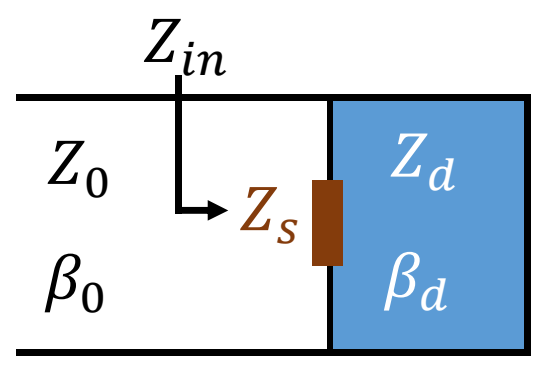

(b)

Figure 4. (a) Schematic design of a radar absorber, (b) Transmission line model of the absorber.

Using the transmission line theory, the impedance of the grounded substrate for normal incidence is given by [31]:

$$
Z_{g}=j Z_{d} \tan \left(\beta_{d} h\right)
$$

where $Z_{d}=\sqrt{\mu_{0} / \epsilon_{0} \epsilon_{r}}$ is the characteristic impedance of the dielectric and $\beta_{d}=\frac{\omega \sqrt{\epsilon_{r}}}{c}$ is the propagation constant in the dielectric. The input impedance, $Z_{i n}$, is given by the parallel combination of the grounded dielectric $\left(Z_{g}\right)$ and the complex sheet $\left(Z_{S}\right)$ :

$$
Z_{i n}=\frac{j Z_{s} Z_{d} \tan \left(\beta_{d} h\right)}{Z_{s}+j Z_{d} \tan \left(\beta_{d} h\right)}
$$

For perfect absorption, the reflexion must satisfy $R=\left(Z_{i n}-Z_{0}\right) /\left(Z_{i n}+Z_{0}\right)=0$. Hence, perfect absorption is obtained when $Z_{i n}=Z_{0}$. The required impedance of the complex sheet, $Z_{\text {req }}$, for perfect absorption, satisfying $Z_{i n}=Z_{0}$ is given by:

$$
Z_{r e q}=\frac{Z_{0} Z_{d} \tan \left(\beta_{d} h\right)}{j Z_{0}+Z_{d} \tan \left(\beta_{d} h\right)}
$$


From Equation (3), it can be seen that the required complex sheet for perfect absorption depends on the permittivity and the thickness of the dielectric. The required complex impedance $\left(Z_{\text {req }}\right)$ of a $3.2 \mathrm{~mm}$ thick FR4 dielectric substrate is plotted according to Equation (3) in Figure 5 in the range of 5-10 GHz and are compared to the complex surface impedance of the UUSR $\left(Z_{s}\right) . Z_{s}$ is the complex surface impedance of the UUSR without the dielectric and ground plane.

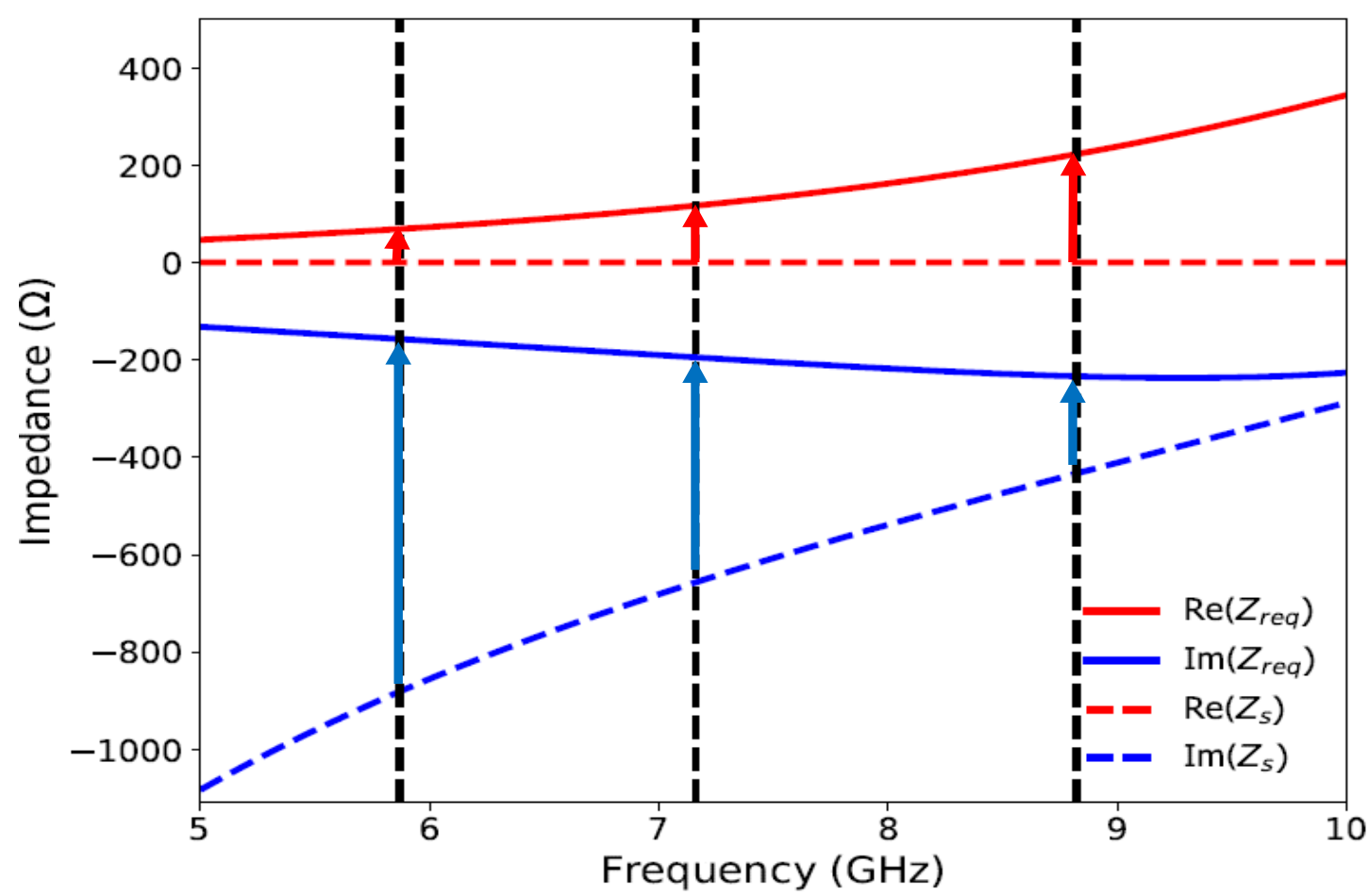

Figure 5. Required real $\left(\operatorname{Re}\left(Z_{\text {req }}\right)\right)$ and imaginary $\left(\operatorname{Im}\left(Z_{\text {req }}\right)\right)$ parts for perfect absorption and real $\left(\operatorname{Re}\left(Z_{s}\right)\right)$ and imaginary $\left(\operatorname{Im}\left(Z_{s}\right)\right)$ parts of the impedance of the UUSR.

It can be observed from Figure 5 that the real part of impedance of the UUSR $\left(\operatorname{Re}\left(Z_{s}\right)\right)$ is very close to zero which is logical as the UUSR is made of copper. It should be noted that positive values of the imaginary parts mean an inductive coupling is taking place and negative values mean that a capacitive coupling is taking place. In our case, $\operatorname{Re}\left(Z_{s}\right)$ being very close to zero and $\operatorname{Im}\left(Z_{s}\right)$ being negative, the surface impedance $Z_{s}$ is capacitive and can be written in the form $Z_{s}=1 / j C \omega$. $C$ is the value of the equivalent capacitance. For a good absorption (if not perfect), $\operatorname{Re}\left(Z_{s}\right)$ and $\operatorname{Im}\left(Z_{s}\right)$ must be as close as possible to $\operatorname{Re}\left(Z_{\text {req }}\right)$ and $\operatorname{Im}\left(Z_{\text {req }}\right)$ respectively. For broadband absorption, firstly, an inductive coupling is required such that $\operatorname{Im}\left(Z_{s}\right)$ increases and becomes close to $\operatorname{Im}\left(Z_{\text {req }}\right)$ and secondly losses must be introduced such that $\operatorname{Re}\left(Z_{s}\right)$ increases and becomes close to $\operatorname{Re}\left(Z_{r e q}\right)$. Placing the UUSR on top of the metal backed lossy FR4 dielectric substrate will increase both $\operatorname{Re}\left(Z_{s}\right)$ and $\operatorname{Im}\left(Z_{s}\right)$. The real part of the surface impedance, $\operatorname{Re}\left(Z_{s}\right)$ will be increased as the dielectric substrate is lossy and the inductive coupling to increase $\operatorname{Im}\left(Z_{s}\right)$ will be produced by anti parallel currents between the UUSR and the ground plane provided that the dielectric is very thin compared to the wavelength. Obviously, electric coupling is also induced in the structure. The figure below depicts the electric and magnetic fields at the three near unity absorption peaks (Figure 6). 


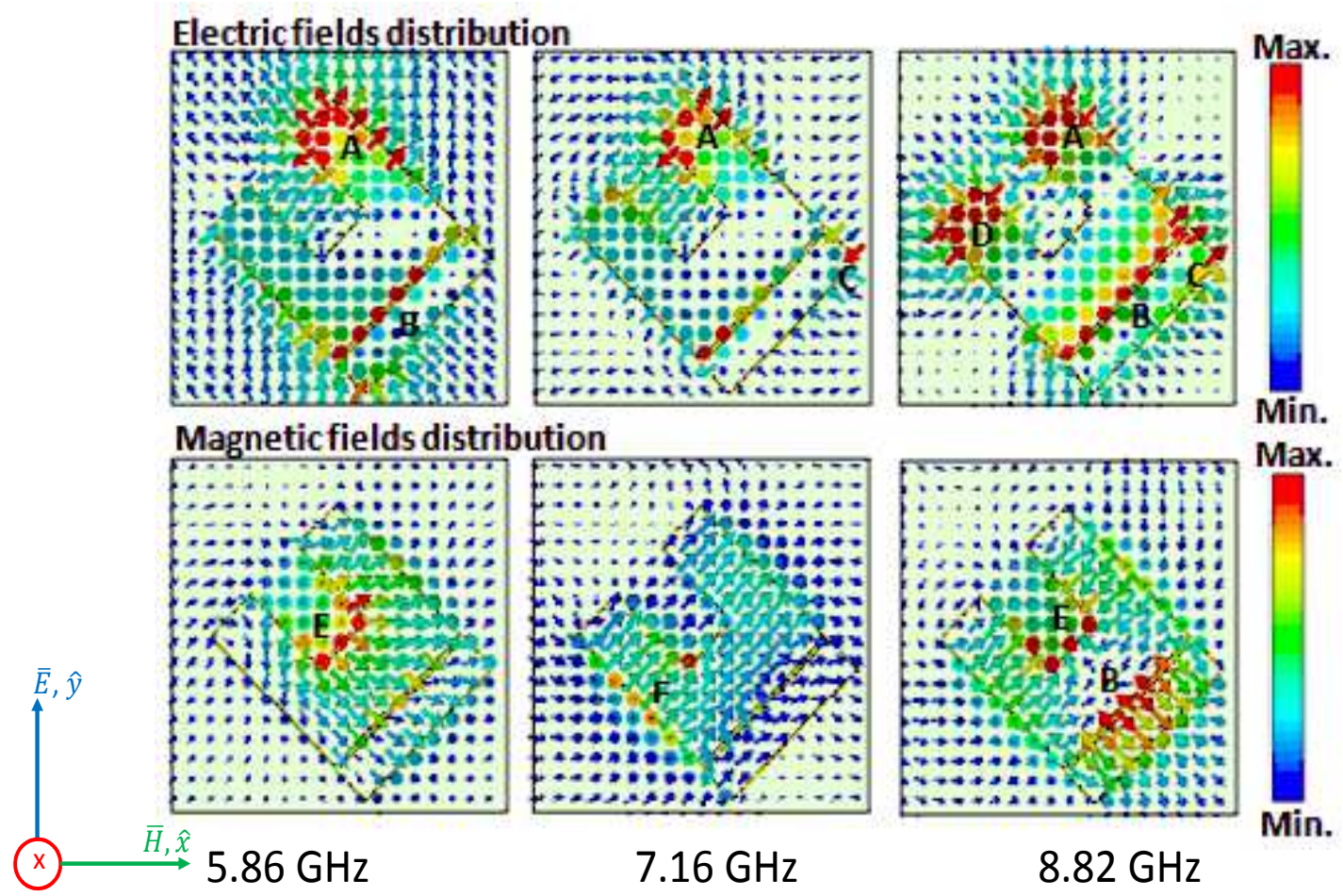

Figure 6. Distribution of electric and magnetic fields on the absorber at $5.86 \mathrm{GHz}, 7.16 \mathrm{GHz}$ and 8.82 $\mathrm{GHz}$ for a linearly polarized TE wave. Different labeled regions correspond to regions where maximum electric or magnetic fields have been observed.

For the first near-unity absorption frequency at $5.86 \mathrm{GHz}$, the electric fields are mainly produced around regions $\mathrm{A}$ and $\mathrm{B}$. The magnetic fields are caused by the anti-parallel currents (not shown in the paper) flowing at regions E. At $7.16 \mathrm{GHz}$, the electric fields are created by regions A and C. The magnetic fields are mainly provoked by the anti-parallel currents flowing at region $\mathrm{F}$ and the ground plane. For the final near unity absorption peak at $8.82 \mathrm{GHz}$, the electric fields are mainly produced around regions A, B, C and D. The magnetic fields are introduced by the anti-parallel currents flowing at regions $\mathrm{E}, \mathrm{B}$ and the ground plane and also by the anti parallel currents flowing between the bottom of the UUSR shape and the top of the strip line. The coupling of electric and magnetic fields led to near unity absorption. As we can observe for the three frequencies, the electric fields are, among others, confined around region A (right hand of the UUSR). Decreasing the length, L1, of the right hand of USSR should decrease the absorption in the whole band. We can check this by tuning the length, L1, of the right hand of the UUSR. It was observed that the capacitance increases and while L1 decreases. Thus the absorption rate is deteriorated when L1 decreases as shown in Figure 7a.The magnetic fields around region $B$ contributed to the third absorption peak only. No magnetic fields were found around region $\mathrm{B}$ for the first and second absorption peaks. Thus, modifying the distance between the strip line and the $U$ shape will affect only the third absorption peak as shown in Figure $7 \mathrm{~b}$.

The selection of dielectric thickness is a very important parameter in the design of a broadband absorber. Increasing the thickness of an absorber does not necessarily increase the absorption bandwidth. What is more important is that the surface the parallel combination of the UUSR impedance and the grounded dielectric impedance matches the impedance of air. Moreover different thicknesses will provide different type of coupling. Figure 8 depicts the absorption rate for different thicknesses. An illumination of linearly polarized TE wave is considered. 

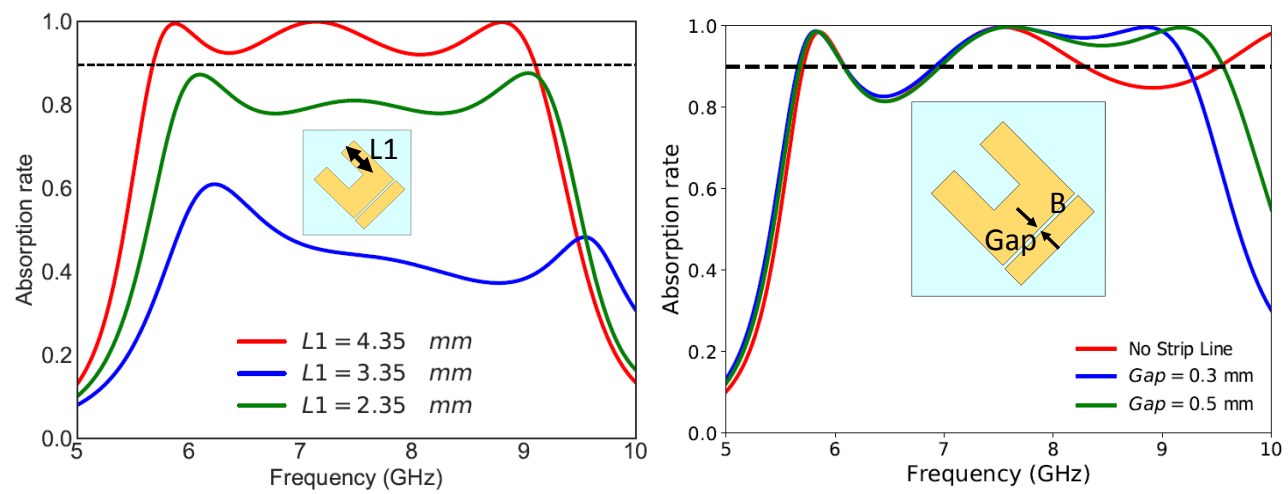

Figure 7. (a) Absorption rate for different values of L1, (b) Absorption rate for different values of the gap. An illumination of linearly polarized TE wave is considered.

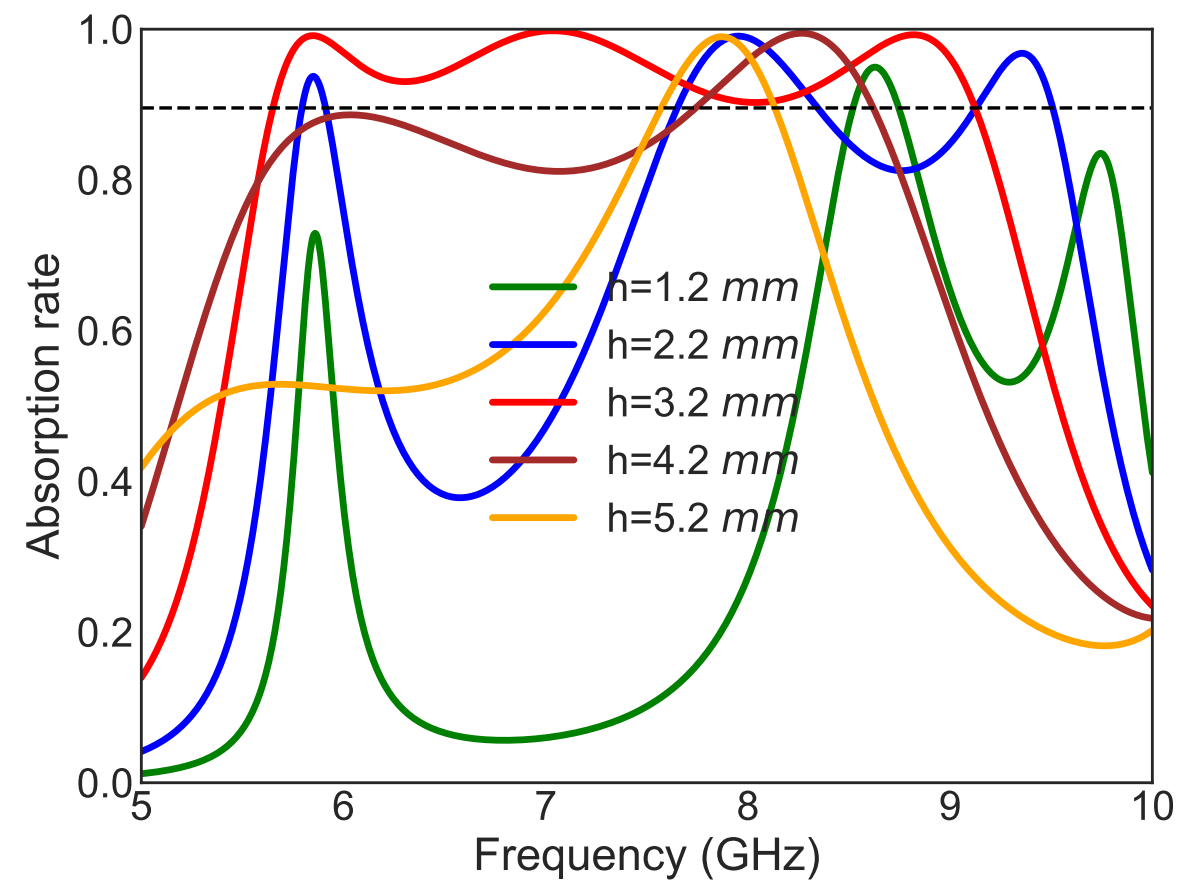

Figure 8. Absorption rate for different values of thickness (h), An illumination of linearly polarized TE wave is considered.

\subsection{Measurements and Verifications}

An experimental prototype with dimensions of $300 \mathrm{~mm} \times 300 \mathrm{~mm}$ and consisting of $19 \times 19$ unit cells was fabricated using conventional printing circuit board (PCB) technology (as shown in Figure 9).

For a linearly polarized TE wave the simulated (solid green line) and measured (red circles) amplitudes of the absorption rate under normal incidence are plotted in Figure 10. Good agreement in terms of bandwidth and absorption rate is reported between simulation and measurement. For the measured absorption rate, the slight shift of the whole frequency band towards lower frequencies can be explained by the fact that the exact value of the permittivity of the fabricated FR4 dielectric. Simulations have shown that a small variation of the value of FR4 (for example 4 instead of 3.92) shifts the whole frequency band towards lower frequencies. 


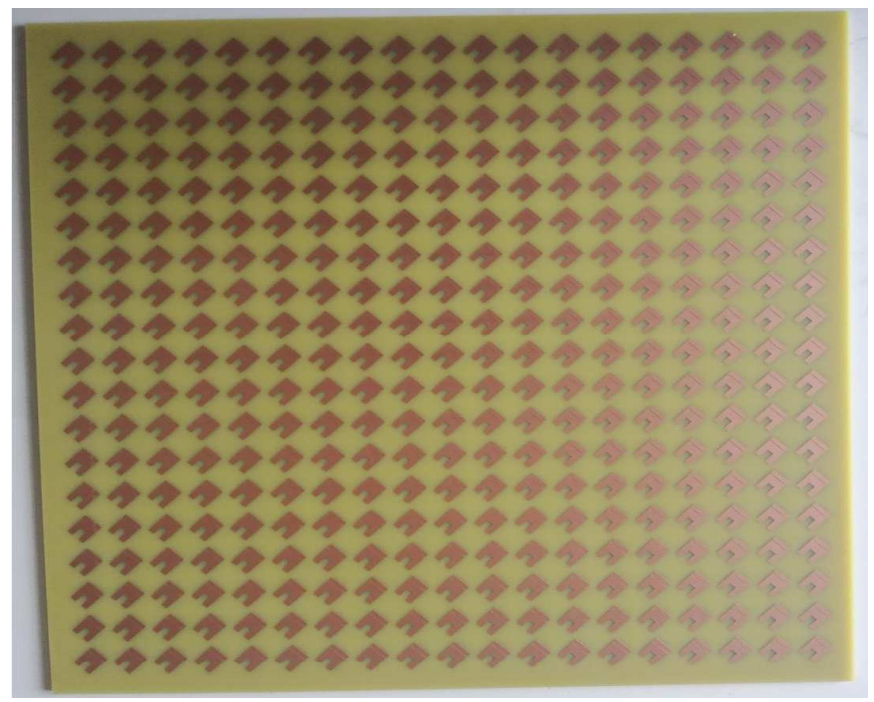

Figure 9. The fabricated $300 \mathrm{~mm} \times 300 \mathrm{~mm}$ prototype.

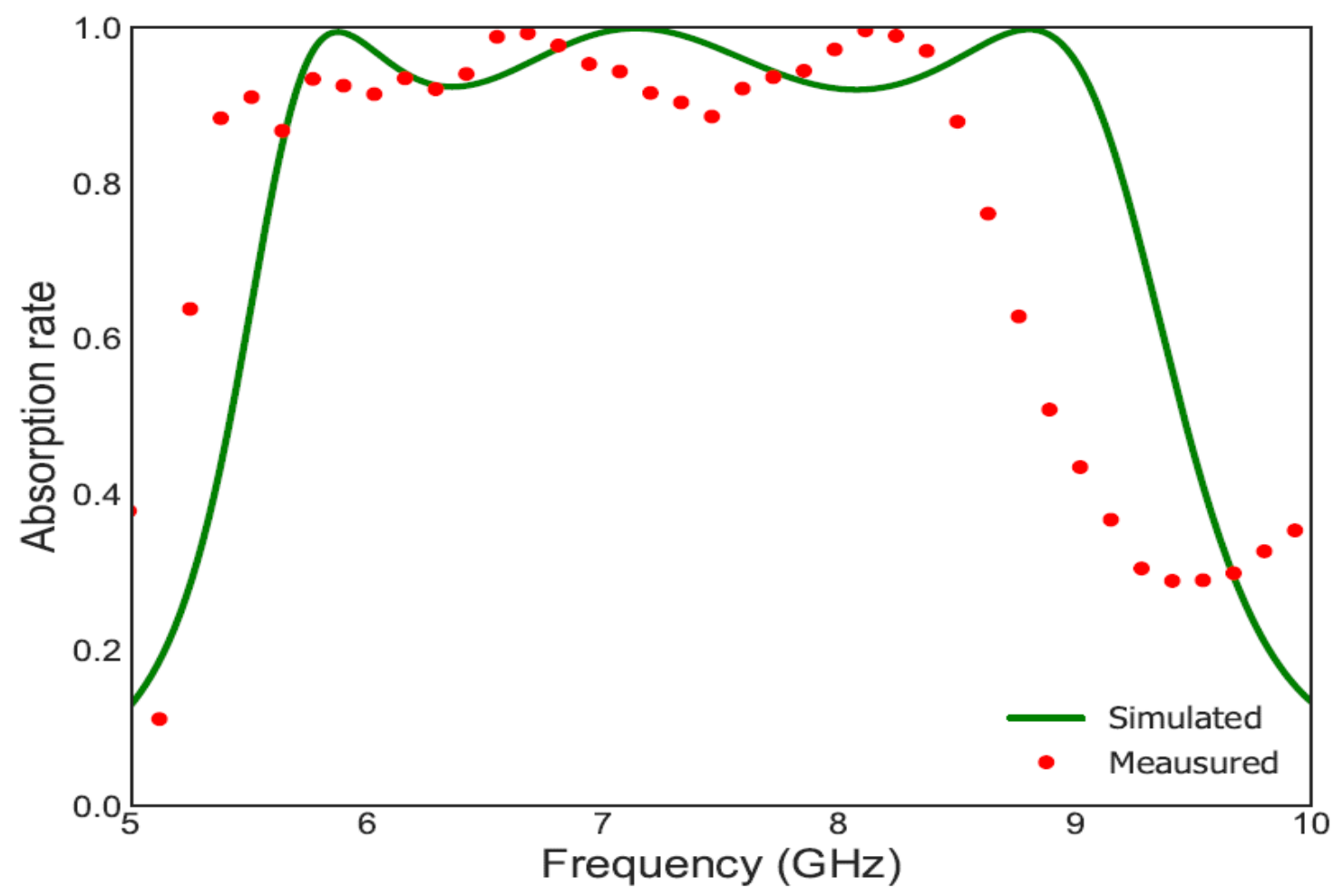

Figure 10. In red circles, the measured absorption rate is plotted and in green the simulated absorption rate is shown. Both are plotted under normal incidence for linearly polarized TE waves.

\section{Discussion}

The performance of an absorber is often judged upon its $90 \%$ absorption rate band to center frequency ratio given by $\left(f_{\max }-f_{\min }\right) / f_{c}$, where $f_{c}$ is the center frequency. This criteria does not take into consideration the thickness of the absorber which can be the most important factor in some applications. The operational bandwidth to thickness ratio to evaluate the performance of the absorber is used this work. Operational bandwidth to thickness ratio is given by $\left(\lambda_{f \min }-\lambda_{f \max }\right) / h$, where $\lambda_{f \min }$ and $\lambda_{\text {fmax }}$ are the wavelengths at $f_{\min }$ and $f_{\max }$ respectively and $\mathrm{h}$ is the thickness of the absorber. 
The bigger is this ratio, the better operational bandwidth to thickness ratio performance an absorber has. Table 1 is a comparison of designed absorbers in this paper with some other absorbers.

Table 1. Performance comparison of our absorber with some other absorbers.

\begin{tabular}{cccc}
\hline Reference & $\mathbf{9 0} \%$ Absorption Bandwidth (GHz) & Thickness $(\mathbf{m m})$ & $\left(\lambda_{\text {fmin }}-\lambda_{\text {fmax }}\right) / \boldsymbol{h}$ \\
\hline$[32]$ & $7-18$ & 4.36 & 6 \\
{$[33]$} & $5.8-12.2$ & 5 & 5.42 \\
{$[34]$} & $8.37-21$ & 3.65 & 5.9 \\
{$[35]$} & $40-134$ & 1 & 5.26 \\
This work & $5.6-9.1$ & 3.2 & 6.43 \\
\hline
\end{tabular}

Even if the proposed design is valid for co-polarization, it can be clearly seen from Table 1 that, a very high performance can be achieved with the proposed resonating element (UUSR). In fact, an operational bandwidth to thickness ratio of 6.43 is obtained making the proposed UUSR very competitive. Further work can be done to enlarge the bandwidth by optimizing multi layers. Communication devices such as detection radars working on the $\mathrm{X}$ band frequency range, one suitable application of the absorber is to reduce back scattering from metallic objects in radomes of military vessels. For example, several antennas and radars are mounted inside radomes which may contain metallic objects such as cable ducts. Reflected electromagnetic waves due to these metallic objects cause EMI critical issues such as saturation of source antennas and radars. The metallic ducts also cause indirect echoes, shadow and blind zones. Covering metallic parts with radar absorbers can decrease considerably the reflections, and hence the indirect echoes. This is illustrated in Figure 11.

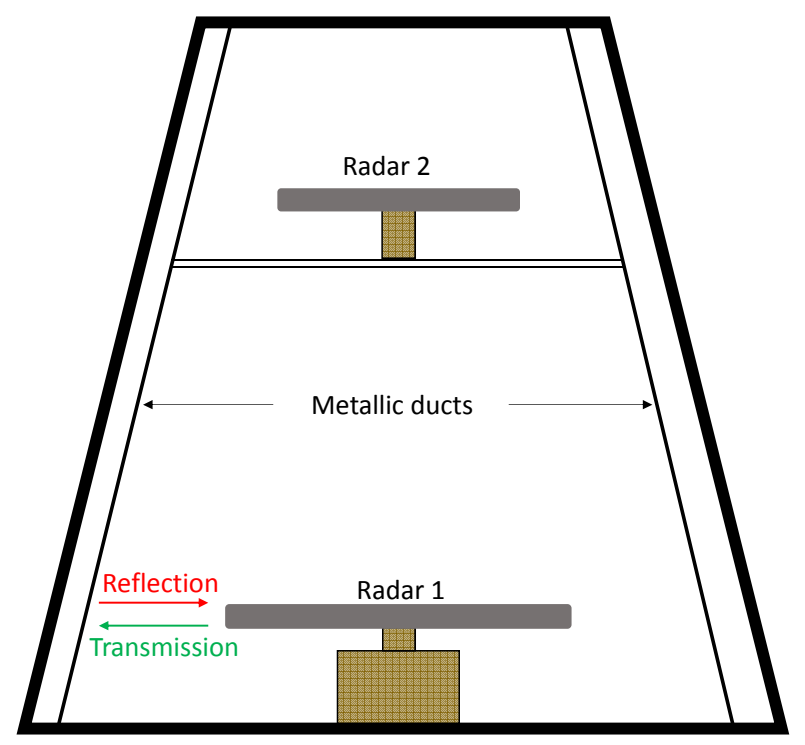

Figure 11. Representation of the profile view of radars mounted inside a radome.

\section{Materials and Methods}

\subsection{Simulation}

Numerical designs and simulations were performed using the commercial software CST Design Studio Suite 2018. Periodic boundary conditions were applied in the numerical model in order to mimic a 2D infinite structure. Floquet ports were used for the excitation of the periodic structure. Simulation results were plotted using a free mathematical programming language tool. 


\subsection{Measurement}

Measurements have been done in an anechoic chamber using a vector network analyzer. Two broadband FLANNR ${ }^{\circledR}$ horn antennas working in the $2-18 \mathrm{GHz}$ frequency band are used as emitter and receiver in reflection configuration. The reflection coefficient is normalized using a sheet of copper as reflecting mirror.

\section{Conclusions}

A single layer low profile broadband co-polarization absorber exhibiting more than $90 \%$ of absorption in the whole band of $5.6 \mathrm{GHz}$ to $9.1 \mathrm{GHz}$. The proposed structure consists of an Underlined U Shape Resonator deposited on a dielectric. We have discussed the absorption mechanism by studying the transmission line model and the magnetic fields. A prototype of the absorber was fabricated and measurement results are in good agreement with numerical results. Due to the proposed original UUSR resonating element, the operational bandwidth to thickness ratio of 6.43 is obtained making the proposed UUSR very competitive and useful for future works. One very important limitation of the proposed absorber is that the absorber is not suitable cross polarization absorption due to the shape of the UUSR. As discussed in the introduction some applications require only co-polarization absorption. Future works can be done in order to make the absorber flexible for non planar objects. This can be done by using flexible dielectrics such as rubber and by optimizing the UUSR. Also further work of optimization must be done in order to use it for non planar objects as the boundary conditions used in this work are for flat targets.

Author Contributions: Conceptualization, T.B.; Formal analysis, K.S. and R.Y.; Methodology, T.B.; Software, T.B.; Supervision, H.H.O.; Validation, H.H.O.; Writing—original draft, T.B.

Acknowledgments: This work was developed in collaboration with the SYSTEMS department of Constructions Mécaniques de Normandie (CMN).

Conflicts of Interest: The authors declare no conflict of interest.

\section{References}

1. Smith, D.R.; Padilla, W.J.; Vier, D.C.; Nemat-Nasser, S.C.; Schultz, S. Composite medium with simultaneously negative permeability and permittivity. Phys. Rev. Lett. 2000, 84, 4184. [CrossRef] [PubMed]

2. Mei, J.; Ma, G.; Yang, M.; Yang, Z.;Wen, W.; Sheng, P. Dark acoustic metamaterials as super absorbers for low-frequency sound. Nat. Commun. 2012, 3, 756. [CrossRef] [PubMed]

3. Watts, C.M.; Liu, X.; Padilla, W.J. Metamaterial electromagnetic wave absorbers. Adv. Mater. 2012, 24 , OP181.

4. Soukoulis, C.M.; Zhou, J.; Koschny, T.; Kafesaki, M.; Economou, E.N. The science of negative index materials. J. Phys. Condens. Matter 2008, 20, 304217. [CrossRef]

5. Zheludev, N.I.; Kivshar, Y.S. From metamaterials to metadevices. Nat. Mater. 2012, 11, 917. [CrossRef] [PubMed]

6. La Spada, L.; Vegni, L. Near-zero-index wires. Opt. Express 2017, 25, 23699-23708. [CrossRef] [PubMed]

7. Vakil, A.; Engheta, N. Transformation optics using graphene. Science 2011, 332, 1291-1294. [CrossRef] [PubMed]

8. La Spada, L.; Vegni, L. Electromagnetic Nanoparticles for Sensing and Medical Diagnostic Applications. Materials 2018, 11, 603. [CrossRef] [PubMed]

9. Ziolkowski, R.W.; Erentok, A. Metamaterial-based efficient electrically small antennas. IEEE Trans. Antennas Propag. 2006, 54, 2113-2130. [CrossRef]

10. Cai, W.; Chettiar, U.K.; Kildishev, A.V.; Shalaev, V.M. Optical cloaking with metamaterials. Nat. Photonics 2007, 1, 224. [CrossRef]

11. Fang, N.; Lee, H.; Sun, C.; Zhang, X. Sub-diffraction-limited optical imaging with a silver superlens. Science 2005, 308, 534-537. [CrossRef] [PubMed]

12. Yahiaoui, R.; Tan, S.; Cong, L.; Singh, R.; Yan, F.; Zhang, W. Multispectral terahertz sensing with highly flexible ultrathin metamaterial absorber. J. Appl. Phys. 2015, 118, 083103. [CrossRef]

13. Landy, N.I.; Bingham, C.M.; Tyler, T.; Jokerst, N.; Smith, D.R.; Padilla, W.J. Design, theory, and measurement of a polarization-insensitive absorber for terahertz imaging. Phys. Rev. B 2009, 79, 125104. [CrossRef] 
14. Tao, H.; Landy, N.I.; Bingham, C.M.; Zhang, X.; Averitt, R.D.; Padilla, W.J. A metamaterial absorber for the terahertz regime: Design, fabrication and characterization. Opt. Express 2008, 16, 7181-7188. [CrossRef] [PubMed]

15. Landy, N.I.; Sajuyigbe, S.; Mock, J.J.; Smith, D.R.; Padilla, W.J. Perfect metamaterial absorber. Phys. Rev. Lett. 2008, 100, 207402. [CrossRef] [PubMed]

16. Sellier, A.; Teperik, T.V.; de Lustrac, A. Resonant circuit model for efficient metamaterial absorber. Opt. Express 2013, 21, A997-A1006. [CrossRef] [PubMed]

17. Yong, Z.; Zhang, S.; Gong, C.; He, S. Narrow band perfect absorber for maximum localized magnetic and electric field enhancement and sensing applications. Sci. Rep. 2016, 6, 24063. [CrossRef] [PubMed]

18. Wang, N.; Tong, J.; Zhou, W.; Jiang, W.; Li, J.; Dong, X.; Hu, S. Novel quadruple-band microwave metamaterial absorber. IEEE Photonics J. 2015, 7, 1-6. [CrossRef]

19. Ye, Q.; Liu, Y.; Lin, H.; Li, M.; Yang, H. Multi-band metamaterial absorber made of multi-gap SRRs structure. Appl. Phys. A 2012, 107, 155-160. [CrossRef]

20. Kazemzadeh, A.; Karlsson, A. Multilayered wideband absorbers for oblique angle of incidence. IEEE Trans. Antennas Propag. 2010, 58, 3637-3646. [CrossRef]

21. Wakatsuchi, H.; Greedy, S.; Christopoulos, C.; Paul, J. Customised broadband metamaterial absorbers for arbitrary polarisation. Opt. Express 2010, 18, 22187-22198. [CrossRef] [PubMed]

22. Yahiaoui, R.; Ouslimani, H.H. Broadband polarization-independent wide-angle and reconfigurable phase transition hybrid metamaterial absorber. J. Appl. Phys. 2017, 122, 093104. [CrossRef]

23. Sood, D.; Tripathi, C.C. Broadband ultrathin low-profile metamaterial microwave absorber. Appl. Phys. A 2016, 122, 332. [CrossRef]

24. Beeharry, T.; Yahiaoui, R.; Selemani, K.; Ouslimani, H.H. A dual layer broadband radar absorber to minimize electromagnetic interference in radomes. Sci. Rep. 2018, 8, 382. [CrossRef] [PubMed]

25. Rozanov, K.N. Ultimate thickness to bandwidth ratio of radar absorbers. IEEE Trans. Antennas Propag. 2000, 48, 1230-1234. [CrossRef]

26. Fan, Y.; Zhang, H.C.; Yin, J.Y.; Xu, L.; Nagarkoti, D.S.; Hao, Y.; Cui, T.J. An active wideband and wide-angle electromagnetic absorber at microwave frequencies. IEEE Antennas Wirel. Propag. Lett. 2016, 15, 1913-1916. [CrossRef]

27. Li, J.; Jiang, J.; He, Y.; Xu, W.; Chen, M.; Miao, L.; Bie, S. Design of a tunable low-frequency and broadband radar absorber based on active frequency selective surface. IEEE Antennas Wirel. Propag. Lett. 2016, 15, 774-777. [CrossRef]

28. Üstün, K.; Turhan-Sayan, G. Broadband LWIR and MWIR metamaterial absorbers with a simple design topology: Almost perfect absorption and super-octave band operation in MWIR band. J. Opt. Soc. Am. B 2017, 34, D86-D94. [CrossRef]

29. Shrestha, S.; Wang, Y.; Overvig, A.C.; Lu, M.; Stein, A.; Negro, L.D.; Yu, N. Indium Tin Oxide Broadband Metasurface Absorber. ACS Photonics 2018. [CrossRef]

30. Padooru, Y.R.; Yakovlev, A.B.; Kaipa, C.S.; Hanson, G.W.; Medina, F.; Mesa, F.; Glisson, A. W. New absorbing boundary conditions and analytical model for multilayered mushroom-type metamaterials: Applications to wideband absorbers. IEEE Trans. Antennas Propag. 2012, 60, 5727-5742. [CrossRef]

31. Tretyakov, S. Analytical Modeling in Applied Electromagnetics; Artech House: London, UK, 2003.

32. Long, C.; Yin, S.; Wang, W.; Li, W.; Zhu, J.; Guan, J. Broadening the absorption bandwidth of metamaterial absorbers by transverse magnetic harmonics of 210 mode. Sci. Rep. 2016, 6, 21431. [CrossRef] [PubMed]

33. Jang, T.; Youn, H.; Shin, Y.J.; Guo, L.J. Transparent and flexible polarization-independent microwave broadband absorber. ACS Photonics 2014, 1, 279-284. [CrossRef]

34. Xiong, H.; Hong, J.S.; Luo, C.M.; Zhong, L.L. An ultrathin and broadband metamaterial absorber using multi-layer structures. J. Appl. Phys. 2013, 114, 064109. [CrossRef]

35. Ling, X.; Xiao, Z.; Zheng, X.; Tang, J.; Xu, K. Ultra-broadband metamaterial absorber based on the structure of resistive films. J. ElEctromagn. Waves Appl. 2016, 30, 2325-2333. [CrossRef]

(C) 2018 by the authors. Licensee MDPI, Basel, Switzerland. This article is an open access article distributed under the terms and conditions of the Creative Commons Attribution (CC BY) license (http:/ / creativecommons.org/licenses/by/4.0/). 